\title{
Unique Mortality Profile in Japanese Patients with COPD: An Analysis from the Hokkaido COPD Cohort Study
}

\author{
Hironi Makita ${ }^{1,2, *}$ \\ Masaru Suzuki id ${ }^{1, *}$ \\ Satoshi Konnol \\ Kaoruko Shimizu' \\ Yasuyuki Nasuhara' \\ Katsura Nagai ${ }^{1,3}$ \\ Yasushi Akiyama (D) ${ }^{3}$ \\ Satoshi Fuke ${ }^{4}$ \\ Hiroshi Saito ${ }^{5}$ \\ Takeshi Igarashi ${ }^{5}$ \\ Kimihiro Takeyabu (iD ${ }^{6}$ \\ Masaharu Nishimura (iD) ${ }^{1,2}$ \\ 'Department of Respiratory Medicine, \\ Faculty of Medicine and Graduate School \\ of Medicine, Hokkaido University, \\ Sapporo, Japan; ${ }^{2}$ Hokkaido Medical \\ Research Institute for Respiratory \\ Diseases, Sapporo, Japan; ${ }^{3}$ Center for \\ Respiratory Diseases, JCHO Hokkaido \\ Hospital, Sapporo, Japan; ${ }^{4}$ Department of \\ Internal Medicine, KKR Sapporo Medical \\ Center, Sapporo, Japan; ${ }^{5}$ Department of \\ Internal Medicine, Hokkaido Chuo Rosai \\ Hospital, Iwamizawa, Japan; ${ }^{6}$ Department \\ of Respiratory Medicine, Otaru Kyokai \\ Hospital, Otaru, Japan
}

*These authors contributed equally to this work

Correspondence: Masaharu Nishimura Department of Respiratory Medicine, Faculty of Medicine and Graduate School of Medicine, Hokkaido University, Sapporo, Japan

Tel +8I II 70659 II

Fax +81117067899

Email ma-nishi@med.hokudai.ac.jp
This article was published in the following Dove Press journal: International Journal of Chronic Obstructive Pulmonary Disease

Purpose: Causes of death may be unique and different in Japanese patients with COPD because they are generally older, thinner, experience fewer exacerbations, and live longer than those in other countries. We investigated the detailed mortality profile in the Hokkaido COPD cohort study, which completed a 10-year follow-up with a very low dropout rate.

Patients and Methods: We prospectively examined the 10-year natural history in 279 Japanese patients with COPD (GOLD 1, 26\%; GOLD 2, 45\%; GOLD 3, 24\%; and GOLD 4, $5 \%$ ). The majority of patients were male, and the average age at baseline was 69 years old. About $95 \%$ of all patients had accurate mortality data. The risk factors for mortality were also analyzed.

Results: During the 10 years, 112 patients $(40 \%)$ died. Their median survival time was 6.1 years (interquartile range: 4.7-7.9 years), and age at death was $79 \pm 6$ years old (mean \pm SD). Respiratory diseases, including pneumonia, were the leading causes of death in $45(40 \%)$, followed by lung cancer in $24(21 \%)$, other cancers in $18(16 \%)$, and cardiovascular diseases in $12(11 \%)$. In particular, lung cancer-related death was equally distributed across all COPD stages, with a higher proportion of lung cancer in the relatively younger generation $(<64$ years old). Older age at baseline, lower BMI, and severer emphysema were significant risk factors for all-cause mortality.

Conclusion: The unique mortality profile observed in this study should be considered when designing strategies for the management of patients with COPD in any geographic region. Keywords: chronic obstructive pulmonary disease, mortality, cause of death, cohort study

\section{Introduction}

Japanese patients with chronic obstructive pulmonary disease (COPD) are generally older, thinner, and experience fewer exacerbations than do their Western counterparts, as shown by a literature search ${ }^{1}$ as well as direct comparisons made among patients with COPD recruited using the same inclusion criteria in various worldwide clinical trials. ${ }^{2,3}$ Thus, the mortality profile of Japanese patients might be unique and different from that reported elsewhere, particularly from the Western society. Generally, cardiovascular diseases, in addition to respiratory problems, are considered major causes of mortality in patients with COPD worldwide. However, this may not be the case in Japanese patients with COPD, as is shown in the Japanese general population, ${ }^{4}$ wherein lung cancer may be a serious cause of mortality. Knowledge about the existence of such a unique mortality profile, if any, would be vitally important in designing future strategies for the management of 
COPD not only in Japan but also in other geographic regions, considering the rapidly aging populations in developed countries.

The Hokkaido COPD cohort study was a multi-center, prospective, observational, cohort study conducted in Japan, which aimed to examine the natural history and prognosis of Japanese patients with COPD. ${ }^{5-9}$ In this study, 279 Japanese patients with COPD were carefully followed up for 10 years, and $95 \%$ of them had accurate mortality data. ${ }^{9}$ Moreover, several longitudinal variables, such as annual changes in body weight and lung function as well as exacerbation frequency, were available, and these may be associated with mortality in patients with COPD. The aims of this study were to clarify the detailed characteristics of causes of death in Japanese patients with COPD, and to examine the relationship of such mortality with baseline variables as well as their longitudinal changes.

\section{Materials and Methods}

\section{Patients}

The patients' details have been described elsewhere. ${ }^{5-9}$ Briefly, Japanese patients with COPD were recruited at Hokkaido University Hospital, Sapporo, Japan, and its nine affiliated hospitals from May 2003 to May 2005. Patients with clinically diagnosed asthma were excluded. During the first follow-up year, the diagnosis was reconfirmed on the basis of spirometric criteria of the Global Initiative for Chronic Obstructive Lung Disease (GOLD) guidelines. ${ }^{10}$ A total of 279 patients with COPD (GOLD 1, 26\%; GOLD 2, 45\%; GOLD 3, 24\%; and GOLD 4, 5\%) were eligible for subsequent follow-up. This study was conducted in accordance with the Declaration of Helsinki. The Ethics Committee of Hokkaido University School of Medicine approved the study protocol (med02-001) and written informed consent was obtained from all patients.

\section{Study Protocol}

On the first visit, demographic information, including gender, age, height, weight, smoking history, medical history and any medications, information on pulmonary symptoms (chronic bronchitis, mMRC dyspnea scale), and comorbidities, was collected. Until the fifth year, information on COPD exacerbation was collected every month. Spirometry before and after bronchodilator inhalation was performed every 6 months. Diffusion capacity testing, chest computed tomography (CT), and health-related quality of life assessed using St. George's Respiratory Questionnaire were performed every year. The severity of emphysema on chest CT scan was visually assessed by three independent pulmonologists according to the modified Goddard scoring system. ${ }^{5}$ Six images were analyzed in three slices in the lungs and an average score of all images was considered as a representative value of the severity of emphysema in each individual. Each image was classified as normal (score 0), up to $5 \%$ affected (score 0.5 ), up to $25 \%$ affected (score 1 ), up to $50 \%$ affected (score 2 ), up to $75 \%$ affected (score 3 ) and more than $75 \%$ affected (score 4 ). When the three independent pulmonologists disagreed in their evaluation, only the score assessed by the majority was taken. Exacerbation was defined as a worsening or new onset of either 1) two major symptoms (increased dyspnea, change in sputum purulence, or increased sputum volume) or 2) any one major symptom plus any minor symptoms (fever, increased cough, or wheezing) that required a prescription change. ${ }^{7}$

After the fifth year, spirometry and diffusion capacity testing were performed every year for those who agreed with the extension of the regular follow-up program until the tenth year. Spirometry data after the diagnosis of lung cancer were not used in this study. Majority of the patients continued to visit outpatient clinics for appropriate medical care even if they dropped out from the regular followup program.

\section{Causes of Death Adjudication}

A committee for mortality adjudication, comprising four physicians (HM, MS, SK, and MN) with clinical and research experience in internal and pulmonary medicine, centrally adjudicated the causes of death for all reported deaths in this study. Information on the fatal event including the death certificate, hospital discharge summary, and other hospital records (medical chart, pathology, radiology, and laboratory data) was collected where available. In cases of death out of each site hospital, the site coordinator or site physician attempted to ascertain information from family or witness interviews. The committee for mortality adjudication reviewed all information and discussed with the aim of developing a consensus. If the committee concluded that additional information might be needed to assign a more accurate cause of death, the case was referred back to the study site hospital in order to obtain additional information. The primary causes of death were classified into respiratory diseases (including respiratory failure, pneumonia, and lung abscess), lung cancer, cancer in other organs, cardiovascular diseases (including heart failure, ischemic heart diseases, aortic aneurysm rupture, 
aortic dissection, cerebral infarction, and cerebral hemorrhage), and other reasons.

\section{Statistical Analysis}

Differences between survivors and non-survivors were analyzed using Student's $t$-test, the Mann-Whitney $U$-test, or Fisher's exact test, as appropriate. Risk factors for mortality were analyzed using the Kaplan-Meier method with the Log-rank test and multivariate Cox proportional hazards models. Covariate selection for inclusion in the models was based on potential confounding variables known to affect COPD mortality. We treated the CT emphysema score and diffusion capacity (carbon monoxide transfer coefficient: Kco) at baseline separately, because they were mutually correlated. The annual changes in body weight and post-bronchodilator $\mathrm{FEV}_{1}$ during the first 5 years were estimated using linear mixedeffects models. For baseline and longitudinal variables found to be significant, classification and regression tree (CART) analysis was used to identify cut-points that discriminated the patients at high risk of all-cause mortality. Statistical significance was defined as $p<0.05$. All analyses were performed using $\mathrm{R}$ version 3.1.2 (The R Foundation, http://www.r-project.org/).

\section{Results}

\section{Ten-Year Follow-Up Status of the Hokkaido COPD Cohort Study}

Figure E1A in the Online Supplement shows the status of the regular follow-up program of the Hokkaido COPD cohort study during the 10 years. Among the 279 patients with spirometry-confirmed COPD by the first year, 102 (37\%) completed the regular follow-up program for 10 years, and $265(95 \%)$ had mortality data during the 10 year follow-up period. Among them, 180 (65\%) discontinued spirometric follow-up during the 10 years (the reasons for discontinuance of spirometric follow-up are shown in Figure E1B in the Online Supplement). The median number of spirometric assessments per subject was 12 (interquartile range [IQR]: 7-16). The median follow-up period for valid spirometry was 6.6 years (IQR: $3.9-10.0$ years) and that for mortality was 9.9 years (IQR: 6.4-10.0 years; Figure 1). During the 10 years, $112(40 \%)$ patients died, $14(5 \%)$ could not be censored, and 153 (55\%) survived. Non-survivors were significantly older and had lower body mass index (BMI), worse lung function, higher CT emphysema scores,

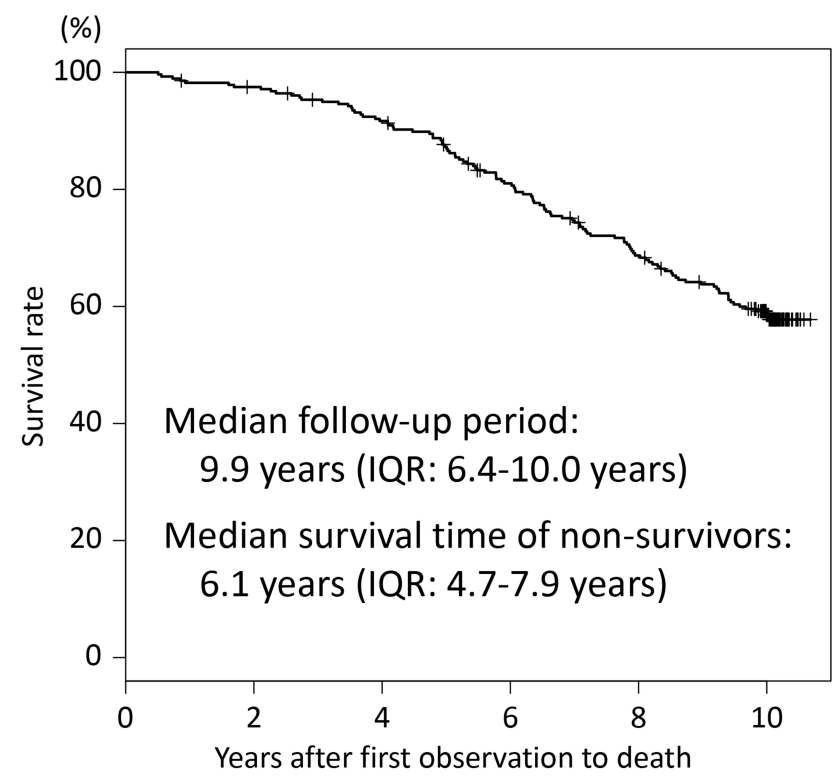

Figure I Kaplan-Meier curve for all-cause mortality for all patients.

and lower leptin/adiponectin ratio than did the survivors (Table 1).

\section{Ten-Year Mortality in Patients with COPD}

The 112 non-survivors during the 10-year follow-up period had a median survival time of 6.1 years (IQR: 4.7-7.9 years) (Figure 1), and their age at death was $79 \pm 6$ years old (mean $\pm \mathrm{SD})$. Among them, $45(40 \%)$ died of respiratory diseases, $24(21 \%)$ from lung cancer, 18 (16\%) from cancer in other organs, $12(11 \%)$ from cardiovascular diseases, and $13(12 \%)$ from other diseases or reasons (Figure 2). The median survival time was not significantly different for the various causes of death (data is not shown). Severer airflow limitation (higher GOLD stage) and older age at baseline were associated with a higher proportion of respiratory diseases as a cause of death, whereas younger age was associated with a higher proportion of lung cancer (Figure 2). In particular, lung cancer-related death was equally distributed across all COPD stages (GOLD 1, 23\%; GOLD 2, 23\%; GOLD 3 and $4,20 \%$ ), and a high proportion of lung cancer-related death $(42 \%)$ was seen in the relatively younger population $(<64$ years old) (Figure 2).

Among the baseline variables, a higher severe CT emphysema score or lower diffusion capacity were associated with all-cause mortality and death from respiratory diseases independent of older age (Table 2). A lower BMI was also associated with death from respiratory diseases (Table 2). A Kaplan-Meier curves for the classification groups 
Table I Baseline Characteristics of 10-Year Survivors and Non-Survivors

\begin{tabular}{|c|c|c|c|}
\hline & Survivors & Non-Survivors & p value \\
\hline Number of patients & 153 & 112 & \\
\hline Age, years old & $67 \pm 8$ & $74 \pm 5$ & $<0.001^{\mathrm{a}}$ \\
\hline Female sex, $\mathrm{N}(\%)$ & II (7) & $3(3)$ & $0.16^{c}$ \\
\hline BMI, $\mathrm{kg} / \mathrm{m}^{2}$ & $23 \pm 3$ & $21 \pm 3$ & $0.00 \mathrm{I}^{\mathrm{a}}$ \\
\hline Current smoker at entry, $\mathrm{N}(\%)$ & $45(29)$ & $28(25)$ & $0.46^{\mathrm{c}}$ \\
\hline Smoking index at entry, pack-years & $66 \pm 32$ & $58 \pm 25$ & $0.07^{\mathrm{a}}$ \\
\hline \multicolumn{4}{|l|}{ Lung function } \\
\hline Post-BD FEV, L & $1.88 \pm 0.67$ & $1.54 \pm 0.61$ & $<0.001^{\mathrm{a}}$ \\
\hline Post-BD FEV ${ }_{1}, \%$ predicted & $68 \pm 22$ & $59 \pm 21$ & $0.004^{\mathrm{a}}$ \\
\hline Post-BD FEV $/$ FVC & $0.53 \pm 0.13$ & $0.48 \pm 0.12$ & $0.00 I^{\mathrm{a}}$ \\
\hline DLco, \% predicted & $81 \pm 24$ & $73 \pm 26$ & $0.009^{\mathrm{a}}$ \\
\hline Kco, \% predicted & $68 \pm 23$ & $57 \pm 24$ & $<0.001^{a}$ \\
\hline \multicolumn{4}{|l|}{ Patient-reported outcomes } \\
\hline Chronic bronchitis, N (\%) & $17(\mathrm{II})$ & $12(11)$ & $1.00^{\mathrm{c}}$ \\
\hline mMRC dyspnea scale & $I(I-2)$ & $2(I-2)$ & $0.04^{\mathrm{b}}$ \\
\hline SGRQ total score & $30 \pm 17$ & $34 \pm 18$ & $0.13^{\mathrm{a}}$ \\
\hline \multicolumn{4}{|l|}{ Laboratory values } \\
\hline Leptin/adiponectin ratio & $0.70(0.35-1.62)$ & $0.39(0.17-0.87)$ & $<0.001^{\mathrm{b}}$ \\
\hline CT emphysema score & $1.00(0.50-2.00)$ & $1.50(0.83-2.33)$ & $<0.001^{b}$ \\
\hline \multicolumn{4}{|l|}{ Comorbidities } \\
\hline Any cardiovascular disease & $30(20)$ & $29(26)$ & $0.24^{c}$ \\
\hline Ischemic heart disease & $10(7)$ & $7(6)$ & $1.00^{c}$ \\
\hline Diabetes & $8(5)$ & $5(4)$ & $1.00^{\mathrm{c}}$ \\
\hline Charlson comorbidity index & $0(0-1)$ & $0(0-1)$ & $0.29^{\mathrm{b}}$ \\
\hline
\end{tabular}

Notes: Fourteen patients whose 10-year survival data were absent were not included in this table. Data are shown as means \pm SD, median

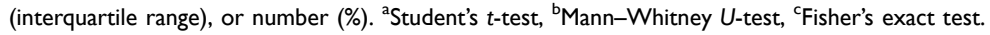

Abbreviations: Post-BD, post-bronchodilator; DLco, carbon monoxide diffusion capacity; Kco, carbon monoxide transfer coefficient.

according to the CT emphysema scores at baseline showed clear separation (Figure 3A). Furthermore, among subjects who survived during the first 5 years, the annual declines in body weight and post-bronchodilator $\mathrm{FEV}_{1}$ during the first 5 years, but not exacerbation frequency, were associated with all-cause mortality and death from respiratory diseases even after adjustment for baseline variables (Table 3). A CART analysis including significant baseline (BMI and CT emphysema score) and longitudinal variables (annual changes in body weight and post-bronchodilator $\mathrm{FEV}_{1}$ during the first 5 years) revealed that CT emphysema score $>3.167$ (emphysema area $>$ around $75 \%$ ) at baseline and an annual loss of body weight $\geq 0.458 \mathrm{~kg}$ /year were associated with a poor prognosis after 5 years of follow-up (Figure 3B).

\section{Discussion}

In this study, we clarified the characteristics of causes of death in Japanese patients with COPD, approximately $70 \%$ of whom were classified as having GOLD spirometric stages 1 and 2. The most frequent cause of death was respiratory diseases $(40 \%)$ including respiratory failure and pneumonia, followed by lung cancer $(21 \%)$ and cancer in other organs (17\%), whereas death from cardiovascular diseases was observed only in $11 \%$ of all COPD stages. We also found that a higher emphysema score and lower diffusion capacity at baseline, as well as a rapid decline in body weight and post-bronchodilator $\mathrm{FEV}_{1}$ during the first 5 years, were significant risk factors for mortality.

Notably, the mean age at death among patients with COPD was 79 years old, which was almost the same age as the average life expectancy for Japanese men (80.79 years old in 2015). This implies that patients with COPD could possibly have a life expectancy similar to that of the general population. As expected, respiratory diseases such as pneumonia and respiratory failure were the most frequent causes of death, and this was especially so in 


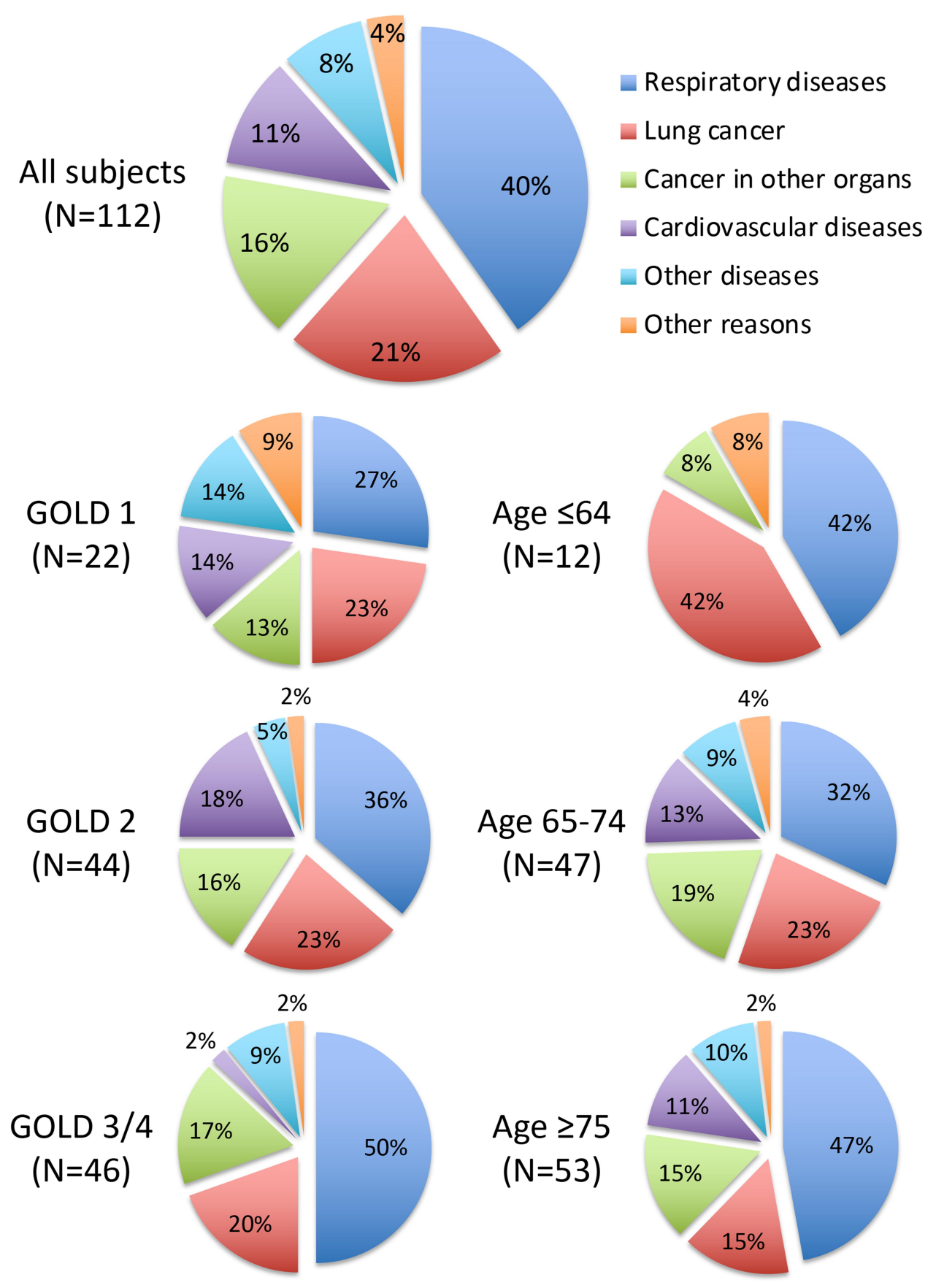

Figure 2 Proportion of causes of death.

patients with severer airflow limitation and older age (Figure 2). In particular, lung cancer was the leading cause of death among younger patients $(<64$ years old). In addition, lung cancer was almost equally distributed, accounting for over 1 of 5 deaths, irrespective of the GOLD spirometric stage (Figure 2). The incidence of lung cancer in patients with COPD has been reported to be high elsewhere, ${ }^{11}$ therefore, efforts for careful screening of lung cancer would be crucial in the management of
COPD, particularly in younger patients with mild or moderate COPD.

In contrast, cardiovascular diseases accounted for only $11 \%$ of deaths in this study, which was significantly less than that previously reported in Western countries or multinational large-scale clinical trials $(19-39 \%),{ }^{11-16}$ where the characteristics of patients with COPD (age, gender, the degree of airflow limitation) were not necessarily similar to this study. This lower prevalence of 
Table 2 Risk Factors of Baseline Variables for All-Cause Mortality (A) and Death from Respiratory Diseases (B)

\begin{tabular}{|c|c|c|c|c|}
\hline \multirow[t]{2}{*}{ A. All-Cause Mortality } & \multicolumn{2}{|l|}{ Kco Excluded } & \multicolumn{2}{|c|}{ CT Emphysema Score Excluded } \\
\hline & Hazard Ratio (95\% Cl) & $p$ value & Hazard Ratio $(95 \% \mathrm{Cl})$ & p value \\
\hline Sex (male) & $2.20(0.65-7.43)$ & 0.19 & $2.23(0.67-7.46)$ & 0.19 \\
\hline Age ( 10 years older) & $1.12(1.08-1.16)$ & $<0.001$ & $1.12(1.08-1.16)$ & $<0.001$ \\
\hline BMI (I kg/m² increase) & $0.92(0.84-1.01)$ & 0.08 & $0.94(0.86-1.04)$ & 0.23 \\
\hline Pack-years (10 pack-years increase) & $0.93(0.87-1.01)$ & 0.07 & $0.94(0.87-1.00)$ & 0.07 \\
\hline mMRC dyspnea scale (I grade increase) & $0.92(0.69-1.23)$ & 0.59 & $0.88(0.66-1.04)$ & 0.39 \\
\hline Post-BD FEV,$\%$ predicted ( $10 \%$ increase) & $0.97(0.88-1.07)$ & 0.54 & $0.93(0.85-1.02)$ & 0.22 \\
\hline Kco \%predicted ( $10 \%$ increase) & - & - & $0.89(0.8 I-0.98)$ & 0.01 \\
\hline CT emphysema score (I point increase) & $1.36(1.08-1.72)$ & 0.009 & - & \\
\hline Charlson Comorbidity Index (I point increase) & $0.92(0.69-1.46)$ & 0.28 & $1.10(0.86-1.40)$ & 0.47 \\
\hline Leptin/adiponectin ratio ( 1 log 10 increase) & $1.00(0.86-1.17)$ & 0.96 & $0.99(0.85-1.15)$ & 0.92 \\
\hline \multirow[t]{2}{*}{ B. Death From Respiratory Diseases } & \multicolumn{2}{|l|}{ Kco Excluded } & \multicolumn{2}{|c|}{ CT Emphysema Score Excluded } \\
\hline & Hazard Ratio (95\% Cl) & $p$ value & Hazard Ratio (95\% Cl) & p value \\
\hline Sex (male) & $4.77 e+07(0-\infty)$ & 1.00 & $1.65 e+07(0-\infty)$ & 1.00 \\
\hline Age ( 10 years older) & $1.17(1.10-1.25)$ & $<0.001$ & $1.16(1.10-1.23)$ & $<0.001$ \\
\hline BMI (I kg/m² increase) & $0.79(0.68-0.92)$ & 0.002 & $0.47(0.72-0.99)$ & 0.04 \\
\hline Pack-years (10 pack-years increase) & $1.04(0.93-1.15)$ & 0.52 & $1.03(0.93-1.14)$ & 0.62 \\
\hline mMRC dyspnea scale (I grade increase) & $0.96(0.58-1.59)$ & 0.86 & $0.94(0.57-1.55)$ & 0.81 \\
\hline Post-BD FEV,$\%$ predicted ( $10 \%$ increase) & $0.89(0.75-1.06)$ & 0.19 & $0.83(0.70-0.99)$ & 0.04 \\
\hline Kco \%predicted ( $10 \%$ increase) & - & - & $0.78(0.67-0.92)$ & 0.003 \\
\hline CT emphysema score (I point increase) & $1.94(1.32-2.86)$ & $<0.001$ & - & - \\
\hline Charlson Comorbidity Index (I point increase) & $1.49(1.05-2.11)$ & 0.02 & $1.33(0.93-1.88)$ & 0.12 \\
\hline Leptin/adiponectin ratio ( $1 \log 10$ increase) & $1.16(0.90-1.49)$ & 0.25 & $1.10(0.87-1.39)$ & 0.41 \\
\hline
\end{tabular}

Notes: $26 \mathrm{I}$ subjects who had 10-year mortality data as well as data of all variables were analyzed. All variables listed were included into the multivariate Cox proportional hazards models. Covariate selection for inclusion in the models was based on potential confounding variables known to affect COPD mortality. CT emphysema score and Kco \%predicted were treated separately, because they were mutually correlated.

Abbreviations: $\mathrm{Cl}$, confidence interval; Post-BD, post-bronchodilator; Kco, carbon monoxide transfer coefficient.

cardiovascular diseases is in line with another report from Japan ${ }^{17}$ as well as a sub-analysis of the TIOSPIR study in Asian patients with COPD.${ }^{18}$ Japan is known to have a much lower mortality from coronary heart disease, which may be attributed to the lower prevalence of hypercholesterolemia and glucose abnormality in Japanese populations than in Western populations. ${ }^{19}$ A lower average BMI related with higher blood adiponectin levels ${ }^{20,21}$ might also contribute to the lower morality from cardiovascular diseases. However, the incidence of coronary heart disease has increased among middle-aged men in the urban areas of Japan, and this has been accompanied by an increase in the prevalence of overweight mainly due to higher saturated fat intake and a lower level of physical activity. ${ }^{22}$ Indeed, the mortality rate from cardiovascular diseases in Japan has been on the rise since 2000 according to data from the Global Burden of Disease. ${ }^{23}$ Therefore, the prevalence of death from cardiovascular diseases among patients with COPD may increase in the future even in Japan, and this will be a potential concern for the clinical management of Japanese patients with COPD.

We found that severer emphysema at baseline was an important risk factor for all-cause and respiratory mortality. This observation is consistent with that of a previous Japanese report. ${ }^{17}$ Indeed, emphysema severity was associated with a rapid annual decline in $\mathrm{FEV}_{1}$ in this cohort. ${ }^{6}$ Further, lower diffusion capacity (suggesting the presence of emphysema) was an important risk factor for the development of lung cancer in another Western cohort. ${ }^{24}$ Collectively, the evaluation of the degree of emphysema on $\mathrm{CT}$ is very important for predicting the prognosis of patients with COPD.

We did not find significant associations with all-cause mortality in the multivariate models for several baseline variables (mMRC dyspnea scale, $\mathrm{FEV}_{1}$, comorbidities) which have been previously reported to be risk factors for mortality in patients with COPD. ${ }^{25-27}$ The explanation for this discrepancy would come from the fact that the 
A
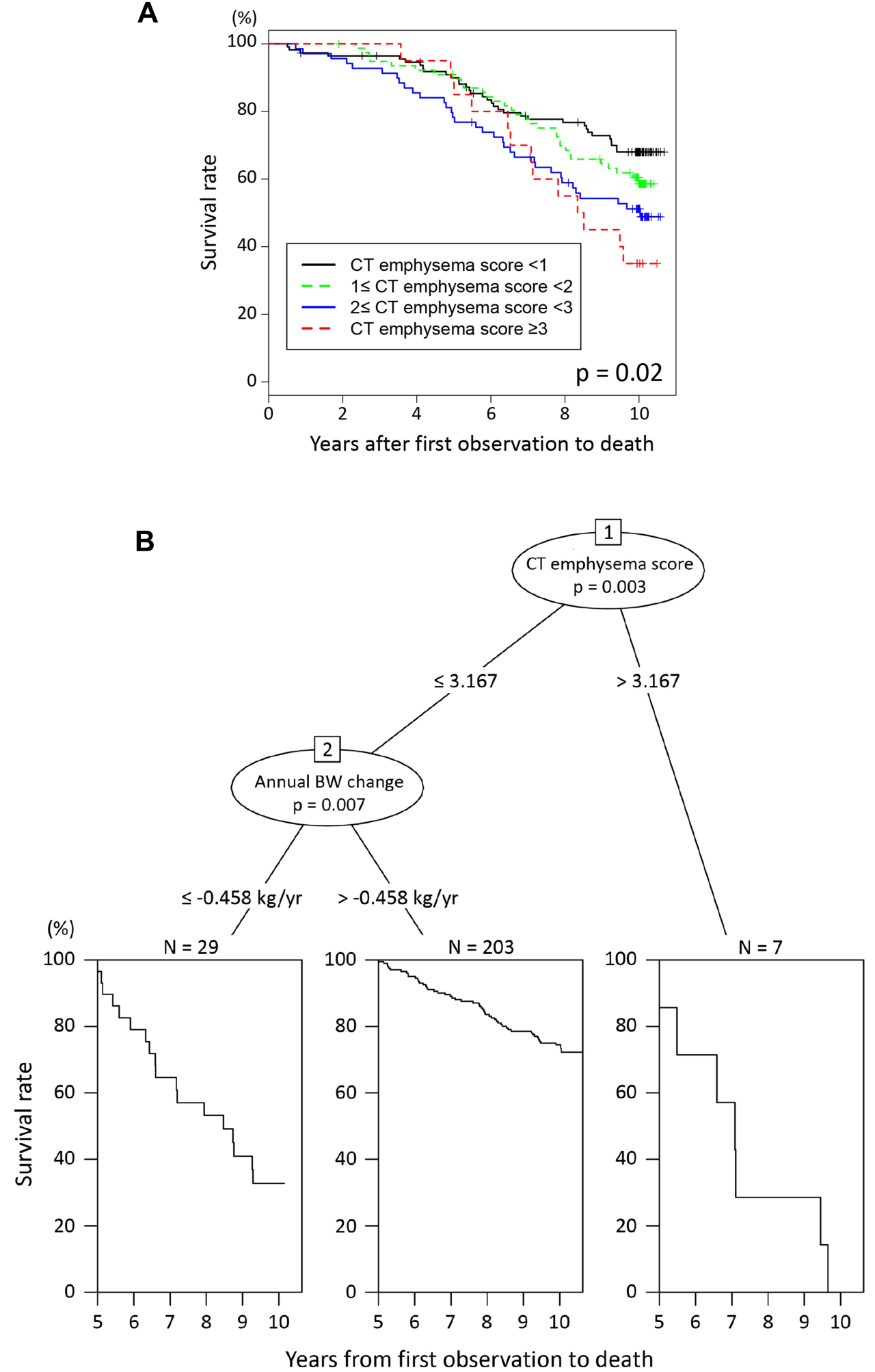

Figure 3 Risk factors for all-cause mortality. (A) Kaplan-Meier curves for all-cause mortality according to the CT emphysema score at baseline. (B) Classification tree produced by CART analysis of risk factors for all-cause mortality during the last 5 years.

Abbreviation: BW, body weight. 
Table 3 Risk Factors of Longitudinal Variables During the First 5 Years for All-Cause Mortality (A) and Death from Respiratory Diseases During the Last 5 Years (B)

\begin{tabular}{|c|c|c|c|c|}
\hline \multirow[t]{2}{*}{ A. All-Cause Mortality } & \multicolumn{2}{|l|}{ Model I } & \multicolumn{2}{|l|}{ Model 2} \\
\hline & Hazard Ratio (95\% Cl) & p value & Hazard Ratio (95\% Cl) & p value \\
\hline Annual body weight change (I kg/year increase) & $0.31(0.16-0.53)$ & $<0.001$ & $0.36(0.19-0.69)$ & 0.002 \\
\hline Annual post-BD FEV , change ( $1 \mathrm{~mL} /$ year increase) & $0.99(0.98-0.997)$ & 0.007 & $0.99(0.97-0.998)$ & 0.02 \\
\hline Exacerbation frequency (per I prescription change event) & $1.09(0.50-2.39)$ & 0.82 & $0.75(0.33-1.69)$ & 0.49 \\
\hline \multirow[t]{2}{*}{ B. Death From Respiratory Diseases } & \multicolumn{2}{|l|}{ Model I } & \multicolumn{2}{|l|}{ Model 2} \\
\hline & Hazard Ratio $(95 \% \mathrm{Cl})$ & p value & Hazard Ratio $(95 \% \mathrm{Cl})$ & p value \\
\hline Annual body weight change (I kg/year increase) & $0.17(0.07-0.42)$ & $<0.001$ & $0.26(0.09-0.75)$ & 0.01 \\
\hline Annual post-BD FEV , change ( $1 \mathrm{~mL} /$ year increase) & $0.98(0.97-0.994)$ & 0.004 & $0.98(0.96-1.00)$ & 0.05 \\
\hline Exacerbation frequency (per I prescription change event) & $2.68(1.11-6.44)$ & 0.03 & $0.82(0.33-2.06)$ & 0.68 \\
\hline
\end{tabular}

Notes: 231 subjects who survived during the first 5 years were analyzed. Model I: Multivariate Cox proportional hazards models using the three longitudinal variables. Model 2: Multivariate Cox proportional hazards models using the three longitudinal variables adjusted by baseline variables (sex, age, BMI, pack-years, mMRC dyspnea scale, post-BD FEV \% \%redicted, CT emphysema score, Charlson Comorbidity Index, leptin/adiponectin ratio).

Abbreviations: $\mathrm{Cl}$, confidence interval; Post-BD, post-bronchodilator.

proportion of patients with mild symptoms and mild to moderate airflow limitation (GOLD 1 and 2) was high in this study. Regarding comorbidities, the Charlson Comorbidity Index was used as a comprehensive index in this study. More disease-specific index, such as the COPD specific comorbidity test (COTE), ${ }^{27}$ may be more discriminative against mortality.

In addition to baseline variables, longitudinal variables, ie, annual changes in body weight and lung function, were associated with mortality in patients with COPD. In particular, the rapid annual body weight loss during the first 5 years was strongly associated with shorter survival thereafter (Figure 3). A high basal metabolic rate due to pathologic conditions is a risk factor for mortality. ${ }^{28}$ In addition, the Baltimore Longitudinal Study of Aging showed that the increased rate of body weight loss had started around 9 years before death for all-cause mortality. ${ }^{29}$ Therefore, the rate of body weight loss, as well as lung function decline, seems to be a useful disease marker for future mortality risk in patients with COPD.

Although the sample size of this study was smaller than that of several previous large-scale observational cohort studies, the strengths of this study were its careful design and intensive analysis. Therefore, it was possible to collect very accurate mortality data for a 10 -year period with a very low dropout rate. In addition, the majority of the patients continued to visit outpatients' clinics regularly even after they dropped out from the study, ${ }^{9}$ and thus the data on causes of death were highly accurate. Nevertheless, this study has some other limitations. First, the unique mortality profile may or may not be applicable to other Asian populations or to other developed Western societies with rapidly aging populations. However, we wish to share the fact that the mortality profile in Japanese patients with COPD is very different from that reported elsewhere, and hope to shed light on new aspects of the natural history of COPD. Second, the majority of the patients were male, and the findings may not necessarily be extrapolated to female patients with COPD. However, the extreme male predominance in Japanese patients with COPD has been reported in several clinical studies. ${ }^{1-3}$ Third, we did not collect exacerbation data for the last 5 years, and this might have affected the mortality profile. Lastly, there may be a survival bias in the recruitment of subjects in this study. The mean age at baseline of whole subjects was 69 years old; therefore, we only recruited those who reached the age and missed those who died at an earlier age, which might be associated with unique mortality profile in this study. However, it must be noted that the mean age of Japanese patients with COPD requited for most clinical studies, including some worldwide clinical trials, was also around 70 years old, which was definitely older than around 65 years old reported from other countries. ${ }^{1-3}$ This fact suggests that the subjects in this study reflect well the reality of Japanese patients with COPD.

\section{Conclusion}

In summary, the most frequent cause of death in Japanese patients with COPD, including all GOLD stages, was respiratory diseases, followed by lung cancer. However, 
death from cardiovascular diseases was far less frequent than that reported for Western populations. In particular, lung cancer-related death was equally distributed across all COPD stages, and a higher proportion of lung cancer was seen in the relatively younger generation ( $<64$ years old). The unique mortality profile observed in this study should be considered when designing strategies for the management of patients with COPD in any geographic region.

\section{Abbreviations}

COPD, chronic obstructive pulmonary disease; GOLD, Global Initiative for Chronic Obstructive Lung Disease; CT, computed tomography; CART, classification and regression tree; Kco, carbon monoxide transfer coefficient; $\mathrm{IQR}$, interquartile range; BMI, body mass index.

\section{Acknowledgments}

The authors would like to thank all of the Hokkaido COPD cohort study investigators (listed in the Online Supplement) for patient recruitment and follow-up, as well as Hideka Ashikaga, Ayako Kondo, and Yuko Takagi of the Central Office of the Hokkaido COPD cohort study (Sapporo, Japan) and the staff of Exam Co., Ltd. (Sapporo, Japan) for data management.

\section{Author Contributions}

All authors made a significant contribution to the work reported, whether that is in the conception, study design, execution, acquisition of data, analysis and interpretation, or in all these areas; took part in drafting, revising or critically reviewing the article; gave final approval of the version to be published; have agreed on the journal to which the article has been submitted; and agree to be accountable for all aspects of the work.

\section{Disclosure}

$\mathrm{MS}, \mathrm{HM}, \mathrm{SK}, \mathrm{KS}, \mathrm{YN}$, and $\mathrm{MN}$ have received grants from Nippon Boehringer Ingelheim and Pfizer during the conduct of the study. MS has received grants from GlaxoSmithKline, AstraZeneca, and Novartis Japan outside the submitted work. MN has received personal fees from Nippon Boehringer Ingelheim, Novartis Japan, and AstraZeneca outside the submitted work. The aforementioned authors report no other potential conflicts of interest in this work. KN, YA, SF, HS, TI, and KT declare that they have no conflicts of interest in this work.

\section{References}

1. Ishii $T$, Nishimura $M$, Akimoto A, James $M H$, Jones $P$. Understanding low COPD exacerbation rates in Japan: a review and comparison with other countries. Int J Chron Obstruct Pulmon Dis. 2018;13:3459-3471. doi:10.2147/COPD.S165187

2. Fukuchi Y, Fernandez L, Kuo HP, et al. Efficacy of tiotropium in COPD patients from Asia: a subgroup analysis from the UPLIFT trial. Respirology. 2011;16(5):825-835. doi:10.1111/j.1440-1843. 2011.01982.x

3. Ichinose M, Taniguchi H, Takizawa A, et al. The efficacy and safety of combined tiotropium and olodaterol via the Respimat ${ }^{\circledR}$ inhaler in patients with COPD: results from the Japanese sub-population of the Tonado $^{\circledR}$ studies. Int $J$ Chron Obstruct Pulmon Dis. 2016;11:2017-2027. doi:10.2147/COPD.S110389

4. Summary tables of mortality estimates by cause, age and sex, by country, 2000-2016 [homepage on the Internet]. World Health Organization; 2018. Available from: https:/www.who.int/healthinfo/ grobal_burden_disease/estimates/en. Accessed June 1, 2019.

5. Makita H, Nasuhara Y, Nagai K, et al. Characterisation of phenotypes based on severity of emphysema in chronic obstructive pulmonary disease. Thorax. 2007;62(11):932-937. doi:10.1136/thx.2006.072777

6. Nishimura M, Makita H, Nagai K, et al. Annual change in pulmonary function and clinical phenotype in chronic obstructive pulmonary disease. Am J Respir Crit Care Med. 2012;185(1):44-52. doi:10.1164/rccm.201106-0992OC

7. Suzuki M, Makita H, Ito YM, et al. Clinical features and determinants of COPD exacerbation in the Hokkaido COPD cohort study. Eur Respir J. 2014;43(5):1289-1297. doi:10.1183/09031936.00110213

8. Suzuki M, Makita H, Konno S, et al. Asthma-like features and clinical course of chronic obstructive pulmonary disease. An analysis from the Hokkaido COPD cohort study. Am J Respir Crit Care Med. 2016;194(11):1358-1365. doi:10.1164/rccm.201602-0353OC

9. Suzuki M, Makita H, Konno S, et al. Annual change in $\mathrm{FEV}_{1}$ in elderly 10-year survivors with established chronic obstructive pulmonary disease. Sci Rep. 2019;9(1):2073. doi:10.1038/s41598-019-38659-8

10. Global strategy for the diagnosis, management, and prevention of COPD 2019 report [homepage on the Internet]. Global Initiative for Chronic Obstructive Lung Disease (GOLD); 2018. Available from: https:/goldcopd.org/wp-content/uploads/2018/11/GOLD-2019-v1. 7-FINAL-14Nov2018-WMS.pdf. Accessed June 1, 2019.

11. Hansell AL, Walk JA, Soriano JB. What do chronic obstructive pulmonary disease patients die from? A multiple cause coding analysis. Eur Respir J. 2003;22(5):809-814. doi:10.1183/ 09031936.03 .00031403

12. Anthonisen NR, Skeans MA, Wise RA, et al. The effects of a smoking cessation intervention on 14.5-year mortality: a randomized clinical trial. Ann Intern Med. 2005;142(4):233-239. doi:10.7326/0003-4819-142-4-200502150-00005

13. McGarvey LP, John M, Anderson JA, Zvarich M, Wise RA; TORCH Clinical Endpoint Committee. Ascertainment of cause-specific mortality in COPD: operations of the TORCH clinical endpoint committee. Thorax. 2007;62(5):411-415. doi:10.1136/thx.2006.072348

14. McGarvey LP, Magder S, Burkhart D, et al. Cause-specific mortality adjudication in the UPLIFT ${ }^{\circledR}$ COPD trial: findings and recommendations. Respir Med. 2012;106(4):515-521. doi:10.1016/j.rmed.2011. 10.009

15. Wise RA, Anzueto A, Cotton D, et al. Tiotropium Respimat inhaler and the risk of death in COPD. $N$ Engl $J$ Med. 2013;369 (16):1491-1501. doi:10.1056/NEJMoa1303342

16. Berry CE, Wise RA. Mortality in COPD: causes, risk factors, and prevention. COPD. 2010;7(5):375-382. doi:10.3109/15412555.2010. 510160

17. Haruna A, Muro S, Nakano Y, et al. CT scan findings of emphysema predict mortality in COPD. Chest. 2010;138(3):635-640. doi:10. 1378/chest.09-2836 
18. Zhong N, Moon HS, Lee KH, et al. TIOtropium safety and performance in Respimat ${ }^{\circledR}$ (TIOSPIR ${ }^{\mathrm{TM}}$ ): analysis of Asian cohort of COPD patients. Respirology. 2016;21(8):1397-1403. doi:10.1111/ resp. 12856

19. Iso H. Lifestyle and cardiovascular disease in Japan. J Atheroscler Thromb. 2011;18(2):83-88. doi:10.5551/jat.6866

20. Tomoda K, Yoshikawa M, Itoh T, et al. Elevated circulating plasma adiponectin in underweight patients with COPD. Chest. 2007;132 (1):135-140. doi:10.1378/chest.07-0227

21. Suzuki M, Makita H, Östling J, et al. Lower leptin/adiponectin ratio and risk of rapid lung function decline in chronic obstructive pulmonary disease. Ann Am Thorac Soc. 2014;11(10):1511-1519. doi:10.1513/AnnalsATS.201408-351OC

22. Kitamura A, Sato S, Kiyama M, et al. Trends in the incidence of coronary heart disease and stroke and their risk factors in Japan, 1964 to 2003: the Akita-Osaka study. $\mathrm{J}$ Am Coll Cardiol. 2008;52 (1):71-79. doi:10.1016/j.jacc.2008.02.075

23. Global Health Data Exchange [homepage on the Internet]. GBD results tool. Available from: http://ghdx.healthdata.org/gbd-resultstool. Accessed July 25, 2020.

24. de Torres JP, Marín JM, Casanova C, et al. Lung cancer in patients with chronic obstructive pulmonary disease- incidence and predicting factors. Am J Respir Crit Care Med. 2011;184(8):913-919. doi:10.1164/rccm.201103-0430OC
25. Antonelli Incalzi R, Fuso L, De Rosa M, et al. Co-morbidity contributes to predict mortality of patients with chronic obstructive pulmonary disease. Eur Respir J. 1997;10(12):2800-2974.

26. Celli BR, Cote CG, Martin JM, et al. The body-mass index, airflow obstruction, dyspnea, and exercise capacity index in chronic obstructive pulmonary disease. $N$ Engl J Med. 2004;350(10):1005-1012. doi:10.1056/NEJMoa021322

27. Divo M, Cote C, de Torres JP, et al. Comorbidities and risk of mortality in patients with chronic obstructive pulmonary disease. Am J Respir Crit Care Med. 2012;186(2):155-161. doi:10.1164/ rccm.201201-0034OC

28. Ruggiero C, Metter EJ, Melenovsky V, et al. High basal metabolic rate is a risk factor for mortality: the Baltimore longitudinal study of aging. J Gerontol a Biol Sci Med Sci. 2008;63(7):698-706. doi:10.1093/gerona/63.7.698

29. Alley DE, Metter EJ, Griswold ME, et al. Changes in weight at the end of life: characterizing weight loss by time to death in a cohort study of older men. Am J Epidemiol. 2010;172(5):558-565. doi:10.1093/aje/kwq168

\section{Publish your work in this journal}

The International Journal of COPD is an international, peer-reviewed journal of therapeutics and pharmacology focusing on concise rapid reporting of clinical studies and reviews in COPD. Special focus is given to the pathophysiological processes underlying the disease, intervention programs, patient focused education, and self management protocols. This journal is indexed on PubMed Central, MedLine and CAS. The manuscript management system is completely online and includes a very quick and fair peer-review system, which is all easy to use. Visit http://www.dovepress.com/testimonials.php to read real quotes from published authors. 